University of Nebraska - Lincoln

DigitalCommons@University of Nebraska - Lincoln

Robert Katz Publications

Research Papers in Physics and Astronomy

March 1987

Inactivation of Dry Enzymes and Viruses by Energetic Heavy lons

M. P. R. Waligorski

Institute of Nuclear Physics, Radzikowskiego 152, 31-342 Krakow, Poland

Kim Sun Loh

University of Nebraska-Lincoln

Robert Katz

University of Nebraska-Lincoln, rkatz2@unl.edu

Follow this and additional works at: https://digitalcommons.unl.edu/physicskatz

Part of the Physics Commons

Waligorski, M. P. R.; Sun Loh, Kim; and Katz, Robert, "Inactivation of Dry Enzymes and Viruses by Energetic Heavy lons" (1987). Robert Katz Publications. 101.

https://digitalcommons.unl.edu/physicskatz/101

This Article is brought to you for free and open access by the Research Papers in Physics and Astronomy at DigitalCommons@University of Nebraska - Lincoln. It has been accepted for inclusion in Robert Katz Publications by an authorized administrator of DigitalCommons@University of Nebraska - Lincoln. 
Published in Radiation Physics and Chemistry 30:3 (1987), pp. 201-208. (Formerly known as International Journal of Radiation Applications and Instrumentation. Part C. Radiation Physics and Chemistry.) http://www.sciencedirect.com/science/journal/0969806X

Copyright (C) 1987 Pergamon Journals Ltd. Used by permission.

\title{
Inactivation of Dry Enzymes and Viruses by Energetic Heavy Ions
}

\author{
M. P. R. Waligórski, ${ }^{1}$ Kim Sun Loh, ${ }^{2}$ and R. Katz ${ }^{2}$ \\ ${ }^{1}$ IAEA Fellow; permanent address: Institute of Nuclear Physics, Radzikowskiego 152, 31-342 Krakow, Poland \\ ${ }^{2}$ Behlen Laboratory of Physics, University of Nebraska-Lincoln, Lincoln, NE 68588, U.S.A. \\ Corresponding author: Robert Katz
}

\begin{abstract}
A newly developed corrected formula for the radial distribution of dose (RDD) has been used to calculate cross sections for the inactivation of dry enzymes and viruses by heavy ions ranging from ${ }_{2}^{4} \mathrm{He}$ to ${ }_{18}^{40} \mathrm{Ar}$ of energies ca. $10 \mathrm{MeV} / \mathrm{a} . \mathrm{m}$.u., spanning a range of LET of $c a .5-2,000 \mathrm{Me} \mathrm{V} \mathrm{cm}^{2} \mathrm{~g}^{-1}$. In comparison with earlier "point-target" calculations of Butts and Katz where a linear range-energy relationship for electrons ( $\delta$-rays) was used, and with "extended-target" calculations of Zhang, Dunn, and Katz, where a power range-energy law and an "uncorrected" RDD formula were applied, the present calculations reproduce all the 72 experimentally measured cross sections and values of the D-37 dose (where available) much more accurately, essentially to within experimental errors. This agreement supports the validity of our phenomenological correction of the RDD formula, suggesting that the theory should rather be tested in the highly structured "thindown" region, at ion energies below ca. $0.5 \mathrm{MeV} /$ a.m.u.
\end{abstract}

\section{Introduction}

Inactivation of dry enzymes and viruses served as an important experimental test of target theory ${ }^{1}$ and of the earliest version of the $\delta$-ray track structure theory. ${ }^{2}$ Track structure theory ${ }^{2-4}$ describes the interaction of a heavy ion with a detector through the joint application of a $c$ hit (or $m$-target) dose-response function after irradiation of this detector with $\gamma$-rays and the radial distribution of dose around the ion's path. The $\gamma$-ray response (inactivation) of enzymes and viruses follows one-or-more hit statistics, as does the response of many other physical detectors: nuclear emulsions, ${ }^{5}$ scintillation counters, and the ferrous sulphate (Fricke) dosimeter, ${ }^{3,6}$ or the aminoacid alanine dosimeter. ${ }^{3,7}$

Butts and Katz, ${ }^{2}$ who derived the formula for the radial distribution of dose before any experimental data on this distribution were available, used the simplifying assumptions of normal ejection of $\delta$-rays, produced according to the classical Rutherford formula, and a linear $\delta$-ray energy-range relationship. The first two assumptions still remain unchanged, as do other elements of the theory: the use of an "effective charge" formula, ${ }^{8}$ and the principle of calculating the response of a detector to a beam of heavy charged particles via the single-particle activation cross section.

To comply with the published measurements of radial distribution of dose in gaseous media, the $\delta$-ray energy-range relationship was replaced by a power law, and an ionization potential term added. ${ }^{9}$

Recently, a further correction in this distribution has been introduced over the radial range $1-10 \mathrm{~nm}^{10}$ to ac- count for primary effects close to the ion's path and to reproduce upon radial integration the value of the stopping power of the ion. The corrected formula now represents quite adequately all the measured and calculated distributions of dose. ${ }^{10}$

The aim of this work is to test the validity of the most recent correction to the radial distribution of dose formula by comparing results of calculations of cross sections for the inactivation of dry enzymes and viruses performed using this formula, with published experimental data, and with results of earlier calculations. ${ }^{2,9}$

Our model is a purely phenomenological one, hence the correctness of any of its elements must be ultimately judged by the accuracy with which results of model calculations reproduce the results of experimental measurements. After this requirement is fulfilled we venture to use the model in a predictive manner, outside the range covered by experiment.

We stress that even in its earliest version of 20 years ago, the model developed by Butts and Katz reproduced the experimentally measured cross sections for enzyme and virus inactivation to within about $20 \%$, offering a consistent explanation of the observed dependence of the measured cross section values on LET. While the application of the form for the radial distribution of dose developed by Zhang et al. ${ }^{9}$ allowed them to reproduce experimental data with an accuracy of $15 \%$ or better, the fact that, when integrated, their form yielded only about a half of the total energy $\left(\mathrm{LET}_{\infty}\right)$ deposited by the ion, yet apparently accounted for the total value of the measured cross section, seemed rather puzzling. 
The set of over 70 cross sections measured for different species of dry enzymes and viruses inactivated by energetic ions of different charge numbers and speeds 11-17 has always provided the best benchmark for testing the validity and the range of applicability for the successive versions of radial distribution of dose formulae applied in track structure theory.

\section{The Model}

Track structure theory has been reviewed elsewhere ${ }^{2-4}$; here we review only those elements of the model which are relevant to the presented calculations.

The $\delta$-ray theory of track structure makes no attempt at following the detailed pathways from the initial array of excitations and ionizations around the path of a heavy ion penetrating the detector medium, to the finally observed endpoint. Instead, the approximation is made that the detector may be calibrated by exposing it to a uniform field of secondary electrons following the gamma irradiation. We take the detector to consist of a set of identical sensitive elements which are sometimes embedded in a passive matrix acting as an energy transfer medium. Nuclear emulsion, where photographic grains are suspended in a gelatine medium, could serve as a good model of such a detector.

In a one-or-more hit detector, one activation (or "hit", such as, e.g. the passage of an electron through the sensitive element) suffices to "turn on" the element (or inactivate an enzyme or virus molecule). For a random distribution, the probability that one of a collection of identical sensitive elements contains $X$ hits when the average number of hits per element is $A$, is given by the cumulative Poisson statistics as $A^{X} \exp (-A) / X$ ! The probability $P$ that there are one or more hits per element is 1 minus the probability that $X=0$, and is given by $P=1$ $\exp (-A)$. The characteristic $\gamma$-ray dose $E_{0}$ is that at which the average number of hits per sensitive element is 1 , hence the probability that any one element of the detector experiences one or more hits after a dose $D \gamma$, is:

$$
P\left(D_{\gamma}\right)=1-\exp \left(-D_{\gamma} / E_{0}\right) \text {. }
$$

The $\gamma$-ray response (inactivation) of a viral or enzymatic system can thus be described by a single number, $E_{0}$, which is measured directly from experiment.

To convert the probability of inactivation after a uniformly distributed dose of secondary electrons following $\gamma$-ray irradiation of the detector to the radial distribution of probability of inactivation around the path of a heavy ion penetrating the detector, $P(t)$, we apply the radial distribution of dose from $\delta$-rays and due to primary effects around the ion's path, $D(t)$, as a transfer function:

$$
P(t)=1-\exp \left(-D(t) / E_{0}\right)
$$

where $t$ is the radial distance from the ion's path.
Integration of $P(t)$ over all radial distances $t$, from 0 to the maximum range of $\delta$-rays. $T$, yields the single-particle activation cross section $\sigma$ :

$$
\sigma=2 \pi \int_{t=0}^{t=T} P(t) t \mathrm{~d} t
$$

which, again, can be directly compared with the value measured experimentally. Namely, the surviving activity $S$ after a fluence $F=\rho D_{\mathrm{i}} / L$ of heavy ions (per $\mathrm{cm}^{2}$ ) of stopping power $L$ and ion dose $D_{\mathrm{i}}(\rho$ is the detector density; in our calculations, for water, $\rho=1 \mathrm{~g} / \mathrm{cm}^{3}$ ), is given by:

$$
S=\exp (-\sigma F)
$$

Equations (2) and (3) illustrate the principle of performing a "point-target" calculation of the single-particle activation cross section $\sigma .^{2}$ In the present work, we apply the corrected formula for the radial distribution of dose around the path of a heavy ion, $D_{2}(t)$, described elsewhere $^{10}$ :

$$
D_{2}(t)=D_{1}(t)(1+K(t))
$$

where:

(a) for $t>B=0.1 \mathrm{~nm}$ :

$$
\begin{aligned}
K(t) & =A\left(\frac{t-B}{C}\right) \exp -\left(\frac{t-B}{C}\right) \\
B & =0.1 \mathrm{~nm} \\
C & =1.5 \mathrm{~nm}+5 \mathrm{~nm} \times \beta
\end{aligned}
$$

and

$$
A=8 \times \beta^{1 / 3}, \text { for } \beta<0.03
$$

or

$$
A=19 \times \beta^{1 / 3}, \text { for } \beta>0.03
$$

(b) for $t<B=0.1 \mathrm{~nm}$ :

$$
K(t)=0
$$

and:

$$
D_{1}(t)=\frac{N e^{4} Z^{* 2}}{\alpha m c^{2} \beta^{2} t}\left[\frac{\left[1-\frac{t+\theta}{T+\theta}\right]^{1 / \alpha}}{t+\theta}\right]
$$

where $D_{1}(t)$ is the dose deposited in a coaxial cylindrical shell of thickness $\mathrm{d} t$ at a distance $t$ from the path of an ion of effective charge $Z^{*}$ moving with a relative velocity $\beta=v / c$ ( $c$ is the speed of light) through the detector medium containing $N$ electrons per $\mathrm{cm}^{3}, m$ is the mass of the electron. The Rutherford cross-section for $(\delta$ ray production from atoms having ionization potential $I=10 \mathrm{eV}$, normal ejection and a power law range $(r)$ energy $(w)$ relationship for electrons, are assumed. The range-energy relationship is based on a two-component 
fit to the available experimental data concerning ranges of electrons in aluminum:

$$
r=k w^{\alpha}
$$

where

$$
k=6 \times 10^{-6} \mathrm{~g} \mathrm{~cm}^{-2} \mathrm{keV}^{-\alpha}
$$

For

$$
w<1 \mathrm{keV}, \alpha=1.079 \text {, }
$$

and for

$$
w>1 \mathrm{keV}, \alpha=1.667 \text {. }
$$

$\theta$ is the "range" of an electron of energy $w=I$ :

$$
\theta=k(0.010 \mathrm{keV})^{1.079}=4.17 \times 10^{-8} \mathrm{~g} \mathrm{~cm}^{-2} .
$$

The kinematically limited maximum $\delta$-ray energy is:

$$
W=2 m c^{2} \beta^{2} /\left(1-\beta^{2}\right) \text {. }
$$

This translates to the maximum range of $\delta$-rays:

$$
T=k W^{\alpha}
$$

where the choice of $\alpha$ (see equation (8)) depends on the velocity $\beta$ of the ion. We calculate:

for

$$
\beta<0.03, \alpha=1.079 \text {, }
$$

and for

$$
\beta>0.03, \alpha=1.667 \text {. }
$$

For water:

$$
\frac{2 \pi N e^{4}}{m c^{2}}=1.369 \times 10^{-7} \frac{\mathrm{erg}}{\mathrm{cm}}=8.5 \mathrm{keV} \mathrm{mm}^{-1} .
$$

Like in the earlier works of Butts and Katz, ${ }^{2}$ and of Zhang et al., ${ }^{9}$ the effective charge of an ion of $Z$ elementary charges, moving with a relative velocity $\beta$ is calculated from the expression of Barkas ${ }^{8}$ :

$$
Z^{*}=Z\left[1-\exp \left(-125 \beta Z^{-2 / 3}\right)\right]
$$

The corrected expression for $D_{2}(t)$ (equations (5.1-5.4)) features a "hump" at radial distances $t=1-10 \mathrm{~nm}$ and reduces to the expression of Zhang et al. ${ }^{9}$ (equation (5.4)) at greater $t$. The "extended target" calculation now proceeds as follows: We calculate the average dose distribution, $E\left(z, \beta, t, a_{0}\right)$ in a sensitive element of radius $a_{0}$, represented by a chunky cylinder of this radius, the axis of which lies at the distance $t$ from the ion's path, by integrating over its volume the appropriate ("corrected" or "uncorrected") formula for the radial distribution of dose (equations (5.1-5.4) or equation (5.4), respectively) and calculate the radial distribution of probability from equation (2). The "extended target" cross section is calculated from equation (3) by replacing $D(t)$ with $E(z, \beta, t$, $a_{0}$ ), where the integration limits are from $=0$ to $T$, given by equation (11).
In all experiments, exposures were performed in "track segment" conditions, i.e. a thin sample was irradiated, hence a constant value of $\beta$, determined by the ion's energy (MeV/a.m.u.), could be assumed in the calculations. Each biological system was irradiated by several ion species at different energies, over a range of particle fluences, and values of cross sections determined from the slope of the surviving activity which decreased exponentially with particle fluence, according to equation (4).

In our calculations, we optimized the value of $E_{0}$ and $a_{0}$ to best fit the whole group of cross sections measured for any enzyme or virus species after all heavy particle bombardments. Where $\mathrm{D}_{\gamma-37}$ values were reported, we attempted to use them as initial values of $E_{0}$. The results depend much more on the choice of $E_{0}$; their dependence on the target radius, $a_{0}$, is fairly weak in the range of $a_{0}=0.5-10 \mathrm{~nm}$.

\section{Results}

Our best fitting values of cross sections for dry virus and enzyme inactivation are compared with the experimental results obtained by several investigators: for T-1 and $\Phi X-174$ phage ${ }^{15,14,18}$ in Table 1, for trypsin ${ }^{13,12,16}$ in Table 2 , for $\beta$-galactosidase, ${ }^{13}$ DNAase, ${ }^{12}$ and lysozyme ${ }^{16}$ in Table 3, for ribonuclease ${ }^{17,11}$ in Table 4, and for invertase $^{17}$ in Table 5. In the leftmost column of these tables, the substances, the referenced investigators, the nominal target radius used in the calculations, and the corresponding illustrations, are given. The next four columns to the right contain experimental data: the bombarding ion, its initial kinetic energy, stopping power (in water), and the measured value of the cross section. Where measured, the $D_{\gamma-37}$ dose for $\gamma$-ray inactivation is given at the top of the cross-section data, in parentheses. The calculated values of the cross sections are given in the sixth column, headed by the best fitting value of $E_{0}$ in parentheses. Finally, the rightmost, seventh, column gives the ratio of the calculated to the experimental cross section values, summarized at the bottom of each set of data by the mean value of the cross-section ratios and their standard deviation. As an estimate of the overall agreement between calculated and measured cross sections, the mean value of the cross-section ratios for the entire set of 74 measured cross sections is $1.00 \pm 0.12$, while the mean ratio of the five $D_{\gamma-37}$ doses is $1.16 \pm 0.17$. The mean relative experimental error in determining the value of the cross section, as based on 10 reported values for the $\mathrm{T}-1$ and $\Phi X-174$ phage, $^{15}$ is $0.06 \pm 0.04$. The remaining authors have not supplied error estimates, and in several cases the values of the cross sections were read directly from the published plots of surviving activity. To assume an overall relative experimental error of 0.10, due to dosimetry, would not be unreasonable.

The measured and calculated values of inactivation cross sections for viruses (Table 1) are displayed as a 
function of ion stopping power $\left(\mathrm{LET}_{\infty}\right)$ in water in Figure 1, and those for enzymes, listed in Tables 2-5, in Figure 2. To facilitate display, groups of data are offset by suitable divisions by powers of 10 along the cross-section (S) and LET (L) axes.

Using the best fitted parameters, $E_{0}$ and $a_{0}$, we have calculated cross sections by continuously varying the relative speed, $\beta$ of the ions for which measurements were reported, and displayed cross sections as a function of the ion stopping power in water. Results of these calculations, extending past the range of mea- surements, together with the experimental data, are displayed in Figure 3 (T-1 and $\Phi X-174$ phage), Figure 4 (invertase and trypsin), and Figure 5 ( $\beta$-galactosidase and lysozyme). A prominent feature of all these graphs is the rise of the cross section values with LET $\infty$ well past the geometrical value $\left(\pi a_{0}^{2}\right)$, ending with "hooks" which indicate the "thindown" 19 region at low ion velocities. Irregularities in the plotted curves at the "thindown" region occur at points of $\beta=0.03$, where different versions of our equations (5.3), (8), and (12) are used.

Table 1. Cross sections for inactivation of dry viruses.

\begin{tabular}{|c|c|c|c|c|c|c|}
\hline \multirow[b]{2}{*}{ Sample } & \multicolumn{3}{|c|}{ Bombardment } & \multicolumn{2}{|c|}{ Cross sections } & \multirow[b]{2}{*}{$\begin{array}{l}\text { Ratio } \\
\mathrm{C} / \mathrm{E}\end{array}$} \\
\hline & Ion & $\begin{array}{l}\text { Kinetic } \\
\text { energy } \\
(\mathrm{MeV})\end{array}$ & $\begin{array}{c}\text { LET in } \\
\text { water } \\
(\mathrm{MeV} / \mathrm{cm})\end{array}$ & $\begin{array}{l}\text { Experimental } \\
\text { (E) } \\
\left(\mathrm{cm}^{2}\right.\end{array}$ & $\begin{array}{l}\text { Calculated } \\
\text { (C) } \\
+14 \text { ) }\end{array}$ & \\
\hline & $\left(D_{\gamma-37}\right)$ & & & (3.9 kGy) & (3.9 kGy) & $(1.0)$ \\
\hline & ${ }^{4} \mathrm{He}_{2}$ & 42 & 172.8 & 435 & 488 & 1.12 \\
\hline \multirow[t]{2}{*}{$T-1$ phage $^{(15)}$} & ${ }^{12} \mathrm{C}_{6}$ & 124 & 1563.6 & 3850 & 2644 & 0.69 \\
\hline & ${ }^{16} \mathrm{O}_{8}$ & 163 & 2774.7 & 5270 & 4251 & 0.81 \\
\hline$a_{0}=10 \mathrm{~nm}$ & ${ }^{19} \mathrm{~F}_{9}$ & 182 & 3652.5 & 5270 & 5333 & 1.01 \\
\hline Fig. 1 & ${ }^{20} \mathrm{Ne}_{10}$ & 202 & 4283.1 & 5400 & 6169 & 1.14 \\
\hline \multirow{3}{*}{ Fig. 3} & ${ }^{40} \mathrm{Ar}_{18}$ & 372 & $13,135.0$ & 13,700 & 16,473 & 1.20 \\
\hline & & & & & \multicolumn{2}{|c|}{ Average: $1.00 \pm 0.21$} \\
\hline & $\left(D_{\gamma-37}\right)$ & & & $(5.3 \mathrm{kGy})$ & (3.9 kGy) & $(0.74)$ \\
\hline \multirow{3}{*}{$T-1$ phage $^{(14)}$} & ${ }^{4} \mathrm{He}_{2}$ & 13.5 & 420.5 & $1040^{\circ}$ & 899.3 & 0.86 \\
\hline & ${ }^{4} \mathrm{He}_{2}$ & 46.5 & 159.4 & 380 & 457.7 & 1.20 \\
\hline & ${ }^{12} \mathrm{C}_{6}$ & 29.5 & 4203.3 & 5400 & 4935.7 & 0.91 \\
\hline$a_{0}=10 \mathrm{~nm}$ & ${ }^{12} \mathrm{C}_{6}$ & 113 & 1683.7 & 3600 & 2780.4 & 0.77 \\
\hline Fig. 1 & ${ }^{16} \mathrm{O}_{8}$ & 35 & 7229.8 & 7900 & 7516.0 & 0.95 \\
\hline \multirow[t]{2}{*}{ Fig. 3} & ${ }^{16} \mathrm{O}_{8}^{\circ}$ & 134 & 3208.2 & 5900 & 4717.4 & 0.80 \\
\hline & & & & & \multicolumn{2}{|c|}{ Average: $0.92 \pm 0.14$} \\
\hline$\Phi \mathrm{X}-174$ & $\left(D_{y-37}\right)$ & & & (5.0 kGy) & (6.8 kGy) & (1.36) \\
\hline phage $^{(15)}$ & ${ }^{4} \mathrm{He}_{2}$ & 42 & 172.8 & $345^{\circ}$ & 304.8 & 0.88 \\
\hline$a_{0}=10 \mathrm{~nm}$ & ${ }^{12} \mathrm{C}_{6}$ & 124 & 1563.6 & 1610 & 1706.0 & 1.06 \\
\hline Fig. 1 & ${ }^{16} \mathrm{O}_{8}$ & 163 & 2774.7 & 2270 & 2678.6 & 1.18 \\
\hline \multirow[t]{2}{*}{ Fig. 3} & ${ }^{40} \mathrm{Ar}_{18}^{\circ}$ & 372 & $13,135.0$ & 10,500 & 10,030 & 0.96 \\
\hline & & & & & \multicolumn{2}{|c|}{ Average: $1.02 \pm 0.13$} \\
\hline
\end{tabular}

Table 2. Cross sections for inactivation of dry enzymes-trypsin.

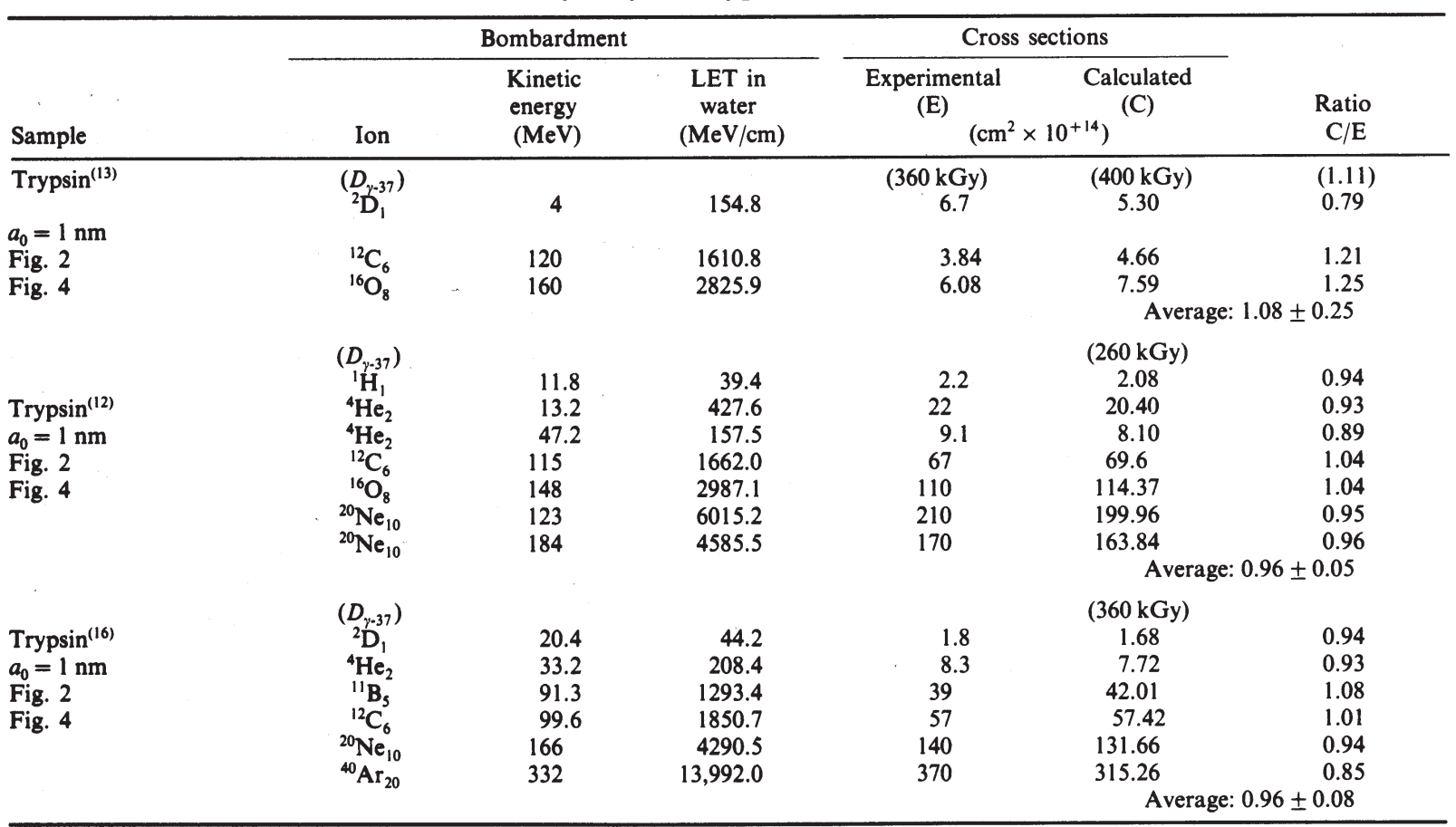


Table 3. Cross sections for inactivation of dry enzymes.

\begin{tabular}{|c|c|c|c|c|c|c|}
\hline \multirow[b]{2}{*}{ Sample } & \multicolumn{3}{|c|}{ Bombardment } & \multicolumn{2}{|c|}{ Cross sections } & \multirow[b]{2}{*}{$\begin{array}{c}\text { Ratio } \\
\mathrm{C} / \mathrm{E}\end{array}$} \\
\hline & Ion & $\begin{array}{l}\text { Kinetic } \\
\text { energy } \\
(\mathrm{MeV})\end{array}$ & $\begin{array}{c}\text { LET in } \\
\text { water } \\
(\mathrm{MeV} / \mathrm{cm})\end{array}$ & $\begin{array}{c}\text { Experimental } \\
(\mathrm{E}) \\
\\
(\mathrm{cm}\end{array}$ & $\begin{array}{l}\text { Calculated } \\
\text { (C) } \\
+14)\end{array}$ & \\
\hline$\beta$-galactosidase ${ }^{(13)}$ & $\left(D_{\gamma, 37}\right)$ & & & $(31 \mathrm{kGy})$ & (41 kGy) & $(1.32)$ \\
\hline$a_{0}=3 \mathrm{~nm}$ & ${ }^{12} \mathrm{C}_{6}$ & 120 & 1610.8 & 280 & 336.6 & 1.20 \\
\hline Fig. 2 & ${ }^{16} \mathrm{O}_{8}$ & 160 & 2825.9 & 450 & 533.2 & 1.19 \\
\hline \multirow[t]{3}{*}{ Fig. 5} & ${ }^{19} \mathrm{~F}_{9}$ & 190 & 3545.1 & 570 & 643.7 & 1.13 \\
\hline & & & & & \multicolumn{2}{|c|}{ Average: $1.17 \pm 0.04$} \\
\hline & $\left(D_{y-37}\right)$ & & & & (180 kGy) & \\
\hline DNA-ase ${ }^{(12)}$ & ${ }_{1}^{y-37 !}$ & 11.8 & 39.4 & 3.4 & 2.99 & 0.88 \\
\hline$a_{0}=1 \mathrm{~nm}$ & ${ }^{4} \mathrm{He}_{2}$ & 13.2 & 427.6 & 26 & 28.3 & 1.09 \\
\hline \multirow[t]{4}{*}{ Fig. 2} & ${ }^{4} \mathrm{He}_{2}$ & 47.2 & 157.5 & 13 & 11.5 & 0.89 \\
\hline & ${ }^{16} \mathrm{O}_{8}$ & 148 & 2987.1 & 170 & 155.7 & 0.92 \\
\hline & ${ }^{20} \mathrm{Ne}_{10}$ & 184 & 4585.5 & 230 & 222.8 & 0.97 \\
\hline & & & & & \multicolumn{2}{|c|}{ Average: $0.95 \pm 0.09$} \\
\hline Lysozyme $^{(16)}$ & $\left(D_{\gamma \cdot 37}\right)$ & & & & (340 kGy) & \\
\hline$a_{0}=1 \mathrm{~nm}$ & ${ }^{1} \mathrm{H}_{1}$ & 11.8 & 39.4 & 1.6 & 1.59 & 0.99 \\
\hline Fig. 2 & ${ }^{4} \mathrm{He}_{2}$ & 13.2 & 427.6 & 17 & 19.96 & 0.94 \\
\hline \multirow[t]{6}{*}{ Fig. 5} & ${ }^{4} \mathrm{He}_{2}$ & 47.2 & 157.5 & 6.3 & 6.24 & 0.99 \\
\hline & ${ }^{12} \mathrm{C}_{6}$ & 115 & 1662.0 & 55 & 55.2 & 1.00 \\
\hline & ${ }^{16} \mathrm{O}_{8}$ & 148 & 2987.1 & 86 & 91.2 & 1.06 \\
\hline & ${ }^{20} \mathrm{Ne}_{10}$ & 123 & 6015.2 & 160 & 160.0 & 1.00 \\
\hline & ${ }^{20} \mathrm{Ne}_{10}$ & 184 & 4585.5 & 120 & 130.9 & 1.09 \\
\hline & & & & & \multicolumn{2}{|c|}{ Average: $1.01 \pm 0.05$} \\
\hline
\end{tabular}

Table 4. Cross sections for inactivation of dry enzymes-ribonuclease.

\begin{tabular}{|c|c|c|c|c|c|c|}
\hline \multirow[b]{2}{*}{ Sample } & \multicolumn{3}{|c|}{ Bombardment } & \multicolumn{2}{|c|}{ Cross sections } & \multirow[b]{2}{*}{$\begin{array}{c}\text { Ratio } \\
\mathrm{C} / \mathrm{E}\end{array}$} \\
\hline & Ion & $\begin{array}{l}\text { Kinetic } \\
\text { energy } \\
(\mathrm{MeV})\end{array}$ & $\begin{array}{c}\text { LET in } \\
\text { water } \\
(\mathrm{MeV} / \mathrm{cm})\end{array}$ & $\begin{array}{l}\text { Experimental } \\
\text { (E) }\left(\mathrm{cm}^{2}\right.\end{array}$ & $\begin{array}{l}\text { Calculated } \\
\text { (C) } \\
+14)\end{array}$ & \\
\hline $\begin{array}{l}\text { Ribonuclease }^{(17)} \\
a_{0}=1 \mathrm{~nm} \\
\text { Fig. } 2\end{array}$ & $\begin{array}{l}\left(D_{\gamma-37}\right) \\
{ }^{1} H_{1} \\
{ }^{2} D_{1}\end{array}$ & $\begin{array}{l}3.69 \\
2.74\end{array}$ & $\begin{array}{r}98.5 \\
203.0\end{array}$ & $\begin{array}{c}(230 \mathrm{kGy}) \\
5.9 \\
9.2\end{array}$ & $\begin{array}{c}(320 \mathrm{kGy}) \\
4.17 \\
8.56 \\
\text { Avera }\end{array}$ & $\begin{aligned} &(1.4) \\
& 0.71 \\
& 0.93 \\
& 0.16\end{aligned}$ \\
\hline $\begin{array}{l}\text { Ribonuclease }^{(11)} \\
a_{0}=1 \mathrm{~nm} \\
\text { Fig. } 2\end{array}$ & $\begin{array}{l}\left(D_{\gamma^{-37}}\right) \\
{ }^{2} \mathrm{D}_{1} \\
{ }^{2} \mathrm{D}_{1} \\
{ }^{2} \mathrm{D}_{1} \\
{ }^{2} \mathrm{D}_{1} \\
{ }^{2} \mathrm{D}_{1} \\
{ }^{2} \mathrm{D}_{1} \\
{ }^{4} \mathrm{He}_{2} \\
{ }^{4} \mathrm{He}_{2} \\
{ }^{4} \mathrm{He}_{2} \\
{ }^{4} \mathrm{He}_{2} \\
{ }^{4} \mathrm{He}_{2} \\
{ }^{4} \mathrm{He}_{2}\end{array}$ & $\begin{array}{l}0.88 \\
1.14 \\
1.58 \\
1.90 \\
2.64 \\
4.32 \\
3.48 \\
3.88 \\
4.36 \\
5.70 \\
6.60 \\
7.60\end{array}$ & $\begin{array}{r}453.3 \\
378.7 \\
300.5 \\
263.5 \\
208.4 \\
146.5 \\
1058.0 \\
988.5 \\
917.9 \\
707.8 \\
698.7 \\
634.6\end{array}$ & $\begin{array}{r}15.4 \\
15.0 \\
13.4 \\
11.8 \\
9.0 \\
6.8 \\
33.4 \\
31.8 \\
29.8 \\
27.2 \\
24.4 \\
21.4\end{array}$ & $\begin{array}{c}(320 \mathrm{kGy}) \\
16.46 \\
14.58 \\
12.18 \\
10.89 \\
8.78 \\
6.21 \\
36.12 \\
34.47 \\
32.66 \\
28.47 \\
26.23 \\
24.13 \\
\text { Avera }\end{array}$ & $\begin{array}{l}1.07 \\
0.97 \\
0.91 \\
0.92 \\
0.98 \\
0.91 \\
1.08 \\
1.08 \\
1.10 \\
1.05 \\
1.07 \\
1.13 \\
0.08 \\
\end{array}$ \\
\hline
\end{tabular}

Table 5. Cross sections for inactivation of dry enzymes-invertase.

\begin{tabular}{|c|c|c|c|c|c|c|}
\hline \multirow[b]{2}{*}{ Sample } & \multicolumn{3}{|c|}{ Bombardment } & \multicolumn{2}{|c|}{ Cross sections } & \multirow[b]{2}{*}{$\begin{array}{l}\text { Ratio } \\
\mathrm{C} / \mathrm{E}\end{array}$} \\
\hline & Ion & $\begin{array}{l}\text { Kinetic } \\
\text { energy } \\
(\mathrm{MeV})\end{array}$ & $\begin{array}{c}\text { LET in } \\
\text { water } \\
(\mathrm{MeV} / \mathrm{cm})\end{array}$ & $\begin{array}{l}\text { Experimental } \\
\text { (E) } \\
\\
\left(\mathrm{cm}^{2}\right.\end{array}$ & $\begin{array}{l}\text { Calculated } \\
\text { (C) } \\
+14 \text { ) }\end{array}$ & \\
\hline $\begin{array}{l}\text { Invertase }{ }^{(11)} \\
a_{0}=3 \mathrm{~nm} \\
\text { Fig. } 2\end{array}$ & $\begin{array}{c}\left(D_{\gamma \cdot 37}\right) \\
{ }^{2} \mathrm{D}_{1} \\
{ }^{2} \mathrm{D}_{1} \\
{ }^{2} \mathrm{D}_{1} \\
{ }^{2} \mathrm{D}_{1} \\
{ }^{2} \mathrm{D}_{1} \\
{ }^{2} \mathrm{D}_{1} \\
{ }^{4} \mathrm{He}_{2} \\
{ }^{4} \mathrm{He}_{2} \\
{ }^{4} \mathrm{He}_{2} \\
{ }^{4} \mathrm{He}_{2} \\
{ }^{4} \mathrm{He}_{2}\end{array}$ & $\begin{array}{l}0.70 \\
0.88 \\
1.14 \\
1.58 \\
2.64 \\
4.32 \\
3.48 \\
4.30 \\
5.76 \\
6.60 \\
7.60\end{array}$ & $\begin{array}{r}528.5 \\
453.3 \\
378.7 \\
300.5 \\
208.4 \\
146.5 \\
1058.0 \\
926.1 \\
765.5 \\
698.7 \\
634.6\end{array}$ & $\begin{array}{r}84 \\
82 \\
79 \\
70 \\
57 \\
41 \\
158 \\
152 \\
149 \\
146 \\
142\end{array}$ & $\begin{array}{c}(47 \mathrm{kGy}) \\
100.21 \\
85.39 \\
79.20 \\
69.52 \\
53.24 \\
39.18 \\
177.29 \\
166.26 \\
148.92 \\
140.42 \\
131.55 \\
\text { Avera } \\
\end{array}$ & $\begin{array}{c}1.19 \\
1.04 \\
1.00 \\
0.99 \\
0.93 \\
0.96 \\
1.12 \\
1.09 \\
1.00 \\
0.96 \\
0.93 \\
0.08 \\
\end{array}$ \\
\hline
\end{tabular}




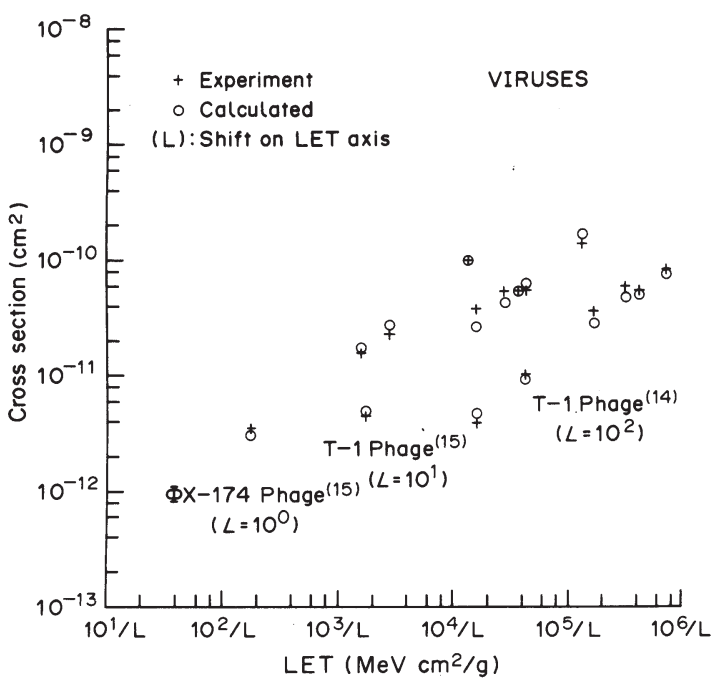

Figure 1. Comparison of experimental ${ }^{14,15}(+)$ and calculated (०) values of inactivation cross sections for dry viruses.

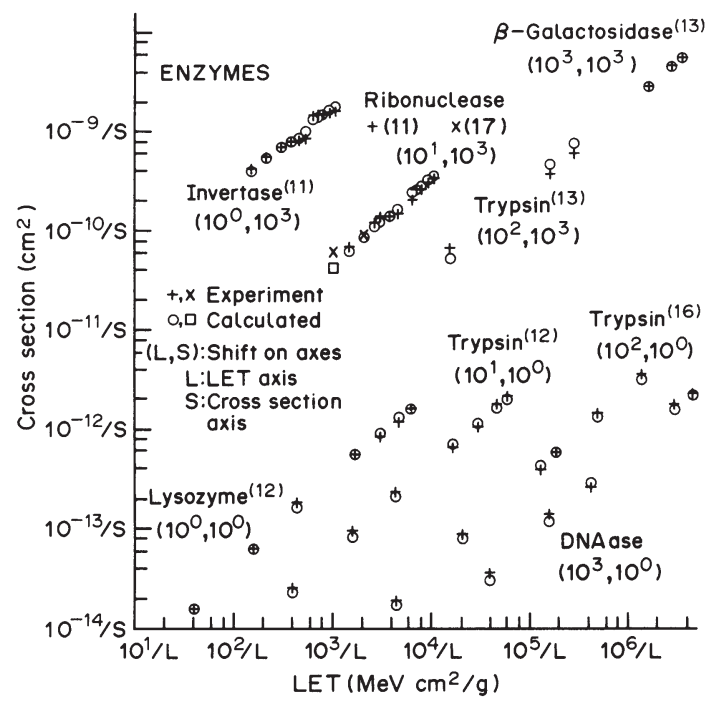

Figure 2. Comparison of experimental $11-13,16,17(\times,+)$ and calculated $(\circ, \square)$ values of inactivation cross section for dry enzymes.

\section{Discussion}

The fit between our results and the experimental data is excellent (essentially within experimental errors) for all viral and enzymatic system investigated in our work. We attribute this result to the application of the new, corrected radial distribution of dose (equation (5)) in our calculations. We stress that we represent any given biological system by one set of parameters, $E_{0}$ and $a_{0}$, which are used to reproduce the experimentally measured values of inactivation cross sections after all heavy ion irradiations of this system. Compared with the results of Zhang et al. ${ }^{9}$ the systematic disagreement between calculated and measured values of cross sections at low
LET has now been eliminated. Again, we attribute this improvement to the correction to the radial distribution of dose used by these authors (equation (5.4)). The effect of introducing the "hump" at radial distances 1-10 $\mathrm{nm}$ (equations (5.1) and (5.2)) on the result of the cross section calculation is most prominent in one-hit detectors of high $E_{0}$ and low $a_{0}$ values, such as alanine $\left(E_{0}=\right.$ $75 \mathrm{kGy}, a_{0}=0.5 \mathrm{~nm}$ ), for bombardments of low atomic number. ${ }^{7}$

All cross section vs. LET dependences shown in Figures 3, 4, and 5 feature "hooks" at the stopping end of the particle track. That such a decrease in the cross section should take place due to the kinematic constraint on the maximum range $T$ of $\delta$-rays (see equations (10) and (11)) was predicted theoretically by Butts and Katz 22 and recently confirmed experimentally as the "thindown" effect, in measurements of inactivation of mammalian cells by UNILAC ions. ${ }^{19}$ The "hooks" are the more prominent the heavier the bombarding ion and the lower the value of detector radiosensitivity, $E_{0}{ }^{2,3}$

In all the experiments investigated in this work, the cross sections due to heavy ion irradiations lie far below the cross section saturation regions, as seen from Figures 3,4 , and 5 . The only exception is the inactivation of T-1 phage by $35 \mathrm{MeV}$ oxygen ions of stopping power ca. $7,000 \mathrm{MeV} \mathrm{cm} \mathrm{g}^{-1}$ (Table 1 and Figure 3), where the corresponding cross section is fairly close to saturation. This observation could qualitatively explain the lack of any "Bragg peak" in the range curves (inactivation cross section vs. depth of beam penetration) for the oxygen beam, as opposed to "Bragg peaks" in cross sections observed for carbon and helium beams by Fluke. ${ }^{14}$

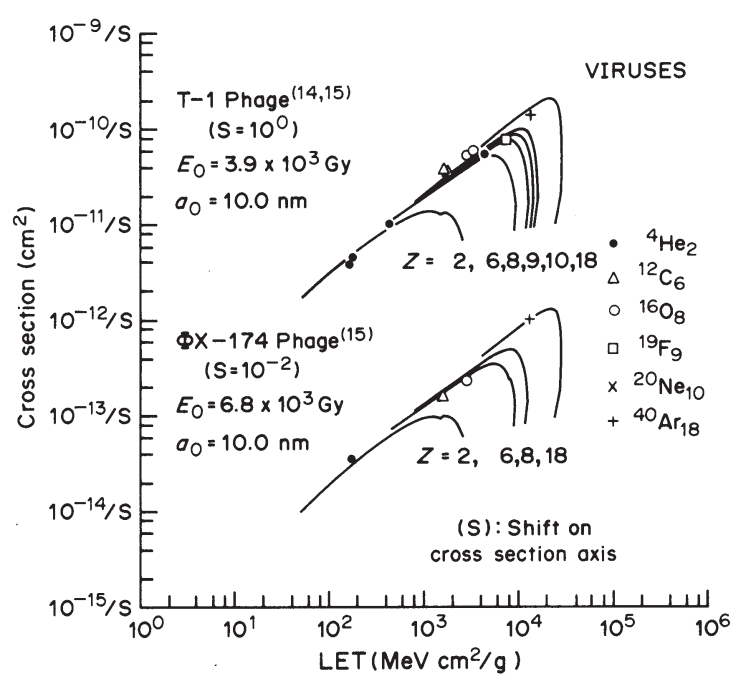

Figure 3. Theoretical dependence of inactivation cross section vs. ion stopping power $\left(\mathrm{LET}_{\infty}\right)$, in water, for T-1 and $\Phi X-174$ phage. Experimental ${ }^{14,15}$ data points after bombardment with ions of different atomic number $Z$ are also plotted. The irregularities in the curves, here visible for He at high LET, result from the discontinuity in equations (5.3), (8), and (12) as the value of $\alpha$ changes from 1.667 to 1.079 at $\beta=0.03$. 


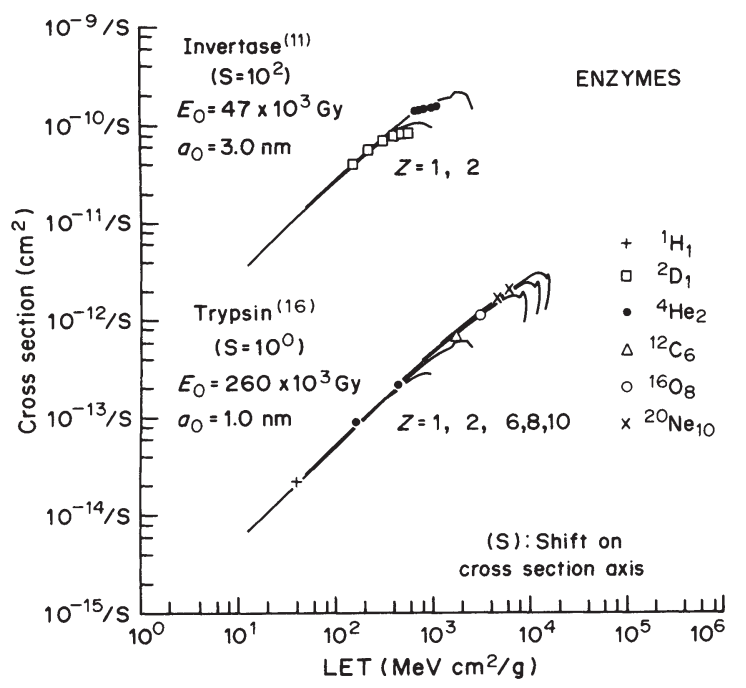

Figure 4. Theoretical dependence of inactivation cross section vs. ion stopping power $\left(\mathrm{LET}_{\infty}\right)$, in water, for invertase ${ }^{11}$ and trypsin. ${ }^{16}$ For further comments, see caption to Figure 3.

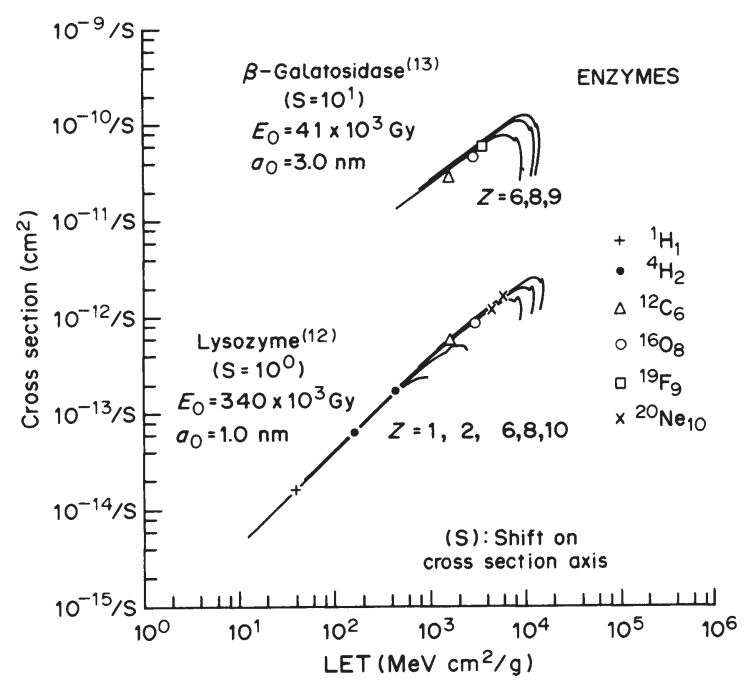

Figure 5. Theoretical dependence of inactivation cross section vs. ion stopping power (LET $\infty)$, in water, for $\beta$-galactosidase $^{13}$ and lysozyme. ${ }^{12}$ For further comments, see caption to Figure 3.

As noted earlier, the results of our calculations depend more on the choice of $E_{0}$ than on the value of $a_{0}$, therefore $E_{0}$ was the main fitted parameter. We were able to fit all the T-1 phage inactivation data of Schambra and Hutchinson ${ }^{15}$ and that of Fluke et al. ${ }^{14}$ using $E_{0}$ $=3.9 \mathrm{kGy}$ (Table 1). The measured values of $D_{\gamma-37}$ reported by these authors were 3.9 and $5.25 \mathrm{kGy}$, respectively. However, in the three sets of data for the inactivation of trypsin (Table 2) for which only Dolphin and Hutchinson ${ }^{13}$ reported the $D_{\gamma-37}$ value of $360 \mathrm{kGy}, E_{0}$ $=400,260$, and $360 \mathrm{kGy}$ were found to best reproduce each set of data.
The fact that the "point target" calculations of Butts and $\mathrm{Katz}^{2}$ are able to reproduce the set of experimental data to within $c a .20 \%$ is an indication that the actual size of the sensitive (inactivation) element used in our calculations plays a relatively minor part in our theory, thus deeming the preoccupation with target size analysis ${ }^{20}$ unwarranted.

\section{Conclusions}

Enzymes and viruses, by the virtue of their biological identicality and simplicity, are excellent systems for testing track theory calculations. Our reproduction, essentially to within experimental errors, of the measured inactivation cross sections for these detectors makes us reasonably confident of the appropriateness of our correction to the radial distribution of dose. This emphasizes the importance of accurate knowledge of the average radial dose distribution over the entire range of radial distances in which energy is deposited, and over the entire range of ion species, their velocities and detector media. Experimental measurements of virus and enzyme inactivation cross sections in the more structured "thindown" region would provide us with a test of the validity of the elements of our calculations at low ion velocities where assumptions concerning the radial distribution of dose and the effective charge are more problematic than in other regions. We need measurements and calculations of the radial distribution of dose at low ion velocities as well as source functions for such calculations in the form of singly- or doubly-differentiated cross sections for $\delta$-ray production. It is rather through such efforts than through calculations and measurements of detailed spectra of energy depositions in nanometre or micrometre subvolumes, or of the spectra of separations of near neighbor ionizations, that a quantitative understanding of heavy ion radiobiology is likely to be achieved.

\section{Acknowledgments}

We thank Dr. Dan Schlitt for his advice on software and hardware problems, and Gary Sinclair and Givargis Danialy for their extensive help with computations and graphics. M. P. R. Waligórski has been supported by a fellowship from the International Atomic Energy Agency (Vienna). This work has been supported by the United States Department of Energy.

\section{References}

1. H. Dertinger and H. Jung, Molecular Radiation Biology. Springer-Verlag, New York, 1970.

2. J. J. Butts and R. Katz, Radiat. Res. 1967, 30, 855.

3. R. Katz, S. C. Sharma, and M. Homayoonfar, In Topics in Radiation Dosimetry (Edited by F. H. Attix). Academic Press, New York, 1972. 
4. R. Katz, Nucl. Track Detection 1978, 2, 1.

5. R. Katz and E. J. Kobetich, Phys. Rev. 1969, 186, 344.

6. R. Katz, G. L. Sinclair, and M. P. R. Waligórski, Nucl. Tracks Radiat. Meas. 1986, 11, 301.

7. M. P. R. Waligórski, G. Danialy, K. S. Loh, and R. Katz, Response of the alanine dosimeter to charged particle and neutron irradiations. In preparation (1987).

8. W. H. Barkas, in Nuclear Research Emulsions I. Techniques and Theory. Academic Press, London, 1963.

9. Chunxiang Zhang, D. E. Dunn, and R. Katz, Radial. Prot. Dosim. 1985, 13, 215.

10. M. P. R. Waligórski, R. N. Hamm, and R. Katz, Nucl. Tracks Radiat. Meas. 1986, 11, 309.

11. R. A. Deering, Radiat. Res. 1956, 5, 233.
12. T. Brustad, Radiat. Res. 1960, (Suppl.) 2, 65.

13. G. W. Dolphin and F. Hutchinson, Radiat. Res. 1960, 13, 403.

14. D. J. Fluke, T. Brustad, and A. C. Birge, Radiat. Res. 1960, 13, 788 .

15. P. E. Schambra and F. Hutchinson, Radiat. Res. 1964, 23 , 514.

16. T. Brustad, Radiat. Res. 1967, (Suppl.) 7, 74.

17. H. Marshal, P. D. Holt, and J. A. B. Gibson, Int. J. Radiat. Biol. 1970, 18, 139.

18. D. J. Fluke and F. Forro Jr, Radiat. Res. 1960, 13, 305.

19. R. Katz, D. E. Dunn, and G. L. Sinclair, Radiat. Prot. Dosim. 1985, 13, 281.

20. G. E. Thomas and D. E. Watt, Radiat. Eff. 1985, 90, 227. 